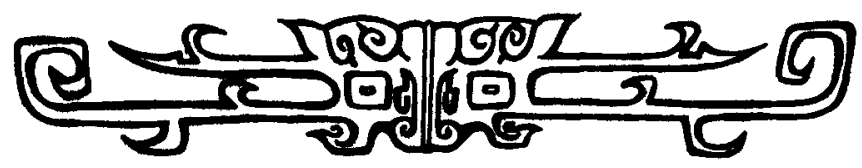

ABSTRACTS

\title{
Dissertations
}

We are making a strong effort to include in this section the most complete information about theses recently finished or topics currently under investigation (those marked $*$ ). The following abstracts are reprinted by permission from volume 36 (1975) of Dissertations Abstracts International, or have been submitted directly by the author. If you are working on a dissertation and it is not listed here, or have completed one and no abstract is included, please inform us of your project and send in an abstract.

Order by publication number and author's name and specify kind of copy (microfilm or xerography) wanted. Send order to Xerox University Microfilms, Dissertation Copies, Post Office Box 1764, Ann Arbor, Michigan 48106. Individuals must send check or money order with their order. Please note that on October 1, 1975 new prices went into effect for on-demand copies of dissertations and masters theses. For this reason we have not indicated price.

\section{PRE-HAN GENERAL}

RESEARCH ON FAKED INSCRIBED BRONZES OF THE PRE-CH'IN PERIOD

CHEUNG, Kwong-yue, Ph.D.

National Taiwan University, Taipei, Taiwan, R. O. C., 1974.

A discussion of the general problems of forgery, and the methods of faking inscriptions and bronze vessels, Many aspects of forgery are illustrated by a group of 58 major inscribed bronzes with texts of 60 characters or more. The existence of "schools" of forgers is graphically illustrated and opens the way for more intensive research along such 1 ines. Criteria of forgery are investigated at some length and critically evaluated. This dissertation has been published and may be purchased by writing to:

Hong Kong Book Shop, 118 Queen's Rd., East, 5 th floor, Flat $A$. Hong Kong

Hsüleh Shang Book Shop, 298 Roosevelt Rd. 3rd. Sec., Taipei, Taiwan, R. 0. C.
STAATSVERFASSUNG UND TERRITORIUM IM ANTIKEN CHINA: UBER DIE AUSBILDUNG EINER TERRITORIALEN STAATSVERFASSUNG. German: Constitution and Territory in Ancient China: On the Development of a Territorial Constitution.]

STUMPFELDT, Hans.

Inaugural-Dissertation, Albert-Ludwigs Universitalt, Freiburg i. B., 1967.

Published as Staatsverfassing ... Statsverfassung (Düsseldorf: Bertelsmann UniversitatsverTag, 1970 $428 \mathrm{pp}$. [Freiburger Studien zu Politik und Gesel1schaft überseeischer Lander, 87).

HUI SHI UND DIE ENTWICKLUNG DES PHILOSOPHISCHEN DENKENS IM ALTEN CHINA. German: Hui Shih and the Development of Philosophical Thought in Ancient China].

Moritz, Ralf.

Universitalt Leipzig, 1969 (Dr., Sektion Afrikaund Nahostwissenschaft). 319 pages.

\section{NEOL I THIC}

\section{AN ARCHAEOLOGICAL SURVEY OF THE P'ULI BASIN WEST} CENTRAL TAIWAN

STAMPS, Richard Brown, Ph. D.

Michigan State University, 1975.

The purpose of the dissertation and the research therein reported is to investigate the origins of agricultural activities in the uplands of west central Taiwan. An attempt is made to shed light in particular on the transition to an agricultural way of life by the people in central Taiwan, and, in general, by extension to a similar shift in other parts of Taiwan and all of East Asia. In doing this I have tried to shed light on the changing relationship between humans and their physical environment. More specifically, an attempt is made to study the reported changes in Taiwan's vegetation over the past fifteen thousand years. Have changes in the vegetation occurred? If so, when? Were these changes related to the movements of people into the area? Were these changes in the vegetation caused by peoples shifting from a hunting and gathering way of 11 fe to a settled village agricultural way of life? Or were there other causes?

It has been reported (Tsukada 1966, 1967; Chang and Struiver 1966; Chang 1969, 1960 A) that several shifts in Taiwan's vegetational cover have occurred in the past fifteen thousand years and that these changes have been induced by human activity. 
Dr. K. C. Chang of Yale University and the Academia Sinica in Nan Kang, Taiwan, noting the reported changes (Tsukada 1966) in Taiwan's vegetation at approximately 9000 and 2500 B.C., developed a hypothesis for further testing that explained these changes. He described them as first a shift from hunting and gathering activities to fruit and root agriculture (9000 B.C.) and later a shift to grain agriculture (c. 2500 B.C.). These hypothesized shifts in subsistence activities were attributed to peoples known archaeologically on Taiwan as the Corded Ware (pottery) peoples and the Lungshanoid peoples. It was the purpose of the author's archaeological research to test these general hypotheses. Evidence for the 9000 B.C. shift was not located; however, several sites were located and dated to the Lungshanoid period.

The major point of the research appears to be that we must remove the uplands of central Taiwan as a possible supportive example showing Southeast Asia as an independent center wherein the domestication of agricultural crops took place. Supportive, verifying evidence for Professor Chang's hypothes is to demonstrate the independent development of domesticated plants in Taiwan could not be found in the uplands of central Taiwan. The earliest agricultural activities in the area appear full blown on the scene. The discovery of these later Lungshanoid remains in the P'uli Basin appears to fit in well with the cultural sequence for western Taiwan (Chang et al. 1974) which was on the receiving end of the peoples and ideas from southeastern China (Chang 1969).

The dissertation contains: First, a review of previous research in the literature to look at the work that has been done and the kinds of questions that are being studied. The second chapter is a statement of certain specific hypotheses to be tested. The third chapter deals with methods for testing the proposed hypotheses, the test implications for each and the data needed to accept or reject the test implications. The fourth chapter deals with the data collection methods used, and the fifth chapter with the analysis of that data. The final chapter deals with the conclusions of the study. It includes a cultural history of the p'uli Basin with a discussion of subsistence activities and a discussion of the proposed hypotheses where they are supported, rejected or modified in light of the recovered data. The importance of this study for Asian prehistory in general is then discussed. The appendix includes additional information regarding the ceramic classification (A), the lithic classification (B), and the sites located $(C)$.

\section{SHANG}

THEME AND SYMBOL IN SHANG AND EARLY WESTERN CHOU RITUAL.

*JOHNSON, Elizabeth Childs

New York University, Institute of Fine Arts
A SEMANTIC ANALYSIS OF THE DISASTER GRAPHS OF PERIOD ONE SHANG DYNASTY ORACLE BONES

MICKEL, Stanley Lewis II, Ph. D. Indiana University, 1976.

The Chinese of the latter part of the Shang dynasty, approximately 1350-1100 B.C., divined about the future through the medium of the scapulae of cattle and the carapaces and plastrons of turtles. After grooves were carved into the reverse of the bones and shells, a question was asked of the oracle and heat was applied to the groove until the material cracked. The resulting crack on the obverse was examined and interpreted as the response of the oracle to the question posed. It appears that approximately one-half the number of questions asked was carved on the bone or shell. Perhaps in ten percent of these inscribed texts, the prognostication or interpretation of the shape of the crack was also recorded in the inscription. An even smaller number of texts contain a verification recording the actual course of events associated with the divination.

Many different topics were asked about in divinations made over the 1 ast 273 years of the Shang. Some of the most common divinations are concerned with the possibilities of some form of disaster occurring as the result of certain activities, or with determining if the ancestors or spirits of the Shang world had been or would be causing some form of disaster. One very common disaster divination simply asks whether any form of disaster would occur during a certain period of time. Scholars have identified 18 different graphs as representing a disaster concept in the oracle texts. Most of these graphs have been thought interchangeable in meaning and in use, as well as generally synonymous. In previous studies of the oracle graphs, scholars have been primarily concerned with identifying the relationships between the oracle graphs and their modern equivalents paying little or no attention to determining exactly how and with what semantic values each of the individual oracle disaster graphs was used during the Shang period.

In this work the primary emphas is is on determining exactly how and with what semantic values each of the disaster graphs was used. The first two chapters are devoted to a brief review of the history of the discovery and study of the oracle inscriptions, followed by a discussion of Chinese and Western theoretical approaches to the decipherment of the oracle graphs. This includes a statement of the theoretical basis used in the study of the disaster graphs in this work. In the third and fourth chapters a critical study is made of previous studies of each of the disaster graphs. This is followed by analys is of the semantic environments in which disaster graphs appear, an analysis of the syntactical patterns in which the individual graphs appear, and an analys is of what the occurrence of different disaster graphs in the same text or in identical syntactical structures may reveal about the semantic values for which the Shang diviner used each graph. The fifth chapter is a summary of the results of the third and fourth chapters. It is followed by supporting charts, finding lists, and a bibliography.

This study demonstrates that the 18 disaster graphs were used for different semantic values, not all of which are concepts of disaster; therefore, it is now necessary to regard each of the disaster graphs as representing a particular concept which is distinct from the concept represented by each of the others. 
Understanding this distinction makes our knowledge of the information contained in the oracle inscriptions that much more nearly complete. 271 pages.

\section{EASTERN CHOU}

DER TEXT CHUANG-TZU (SŌSHI) IN DER DEUTUNG DES PHILOSOPHEN MITSUJI FUKUNAGA. German: The text of Chuang-tzu (Japanese: Sōshi) in the Interpretive Writing of the Philosopher Mitsuji Fukunaga (1918-)]

KOJIMA, Hajime, Ph. D. Julius-Maximilians-Universität Würzburg, 1972 (Dr. Philosophische Fakultăt).

Published as Der Text...Fukunaga (Würzburg, 1971. 182 pp.) LE MUTIANZIZHUAN 楾天子傅. TRADUCTION ANNOTÉE--
ETUDE CRITIQUE.

MATHIEU, Remi, Ph. D.

Paris, 1973

These de 3ème cycle.

DER ,CHINESISCHE LEGALISMUS (Fa chia) UNTER BESONDERER BERUCKSICHTIGUNG SEINER RECHTSPOSITIVISTISCHEN

ELEMENTE, [German: The Chinese Legalist School (Fa chia) with Particular Consideration of Its LawOriented Elements 7

TAI, Tong-schung, Ph. D.

Johannes Gutenberg Universistắt Mainz, 1969

(Dr., Rechts-und Wirtschaftswissenschafliche Fakultät).

\section{HAN}

THE POETRY OF TS'AO P'I (187-226)

FUSEK, Lois, Ph. D.

Yale University, 1975

The late second and the early third century of the Christian era witnessed a rapid political decline in China, culminating in the fall of the Han dynasty in A.D. 220. But in the field of literature, it was an era of immense creativity and experimentation. Poems of purely five syllable lines came to replace the four syllable line imitative of the Book of Songs. Folk songs and poetry exerted a deep influence on the poets who titled their own compositions after folk songs and shaped popular themes and rhythms to their own advantage. The fu 異武, formerly a vehicle for extended and exaggerated description, became shorter and more lyrical. Additionally, literature, which hitherto had not been clearly distinguished from writing in general, now came to be viewed as something separate, and this new attitude fostered the development of literary theory and criticism. While the age had many great poets, perhaps no one better reflects the changes taking place than Ts'ao P'i 曹五 $(187-226)$.

Ts'ao $P^{\prime} i$ figures importantly in the Chinese literary tradition as a poet who experimented with new forms and themes, and most significantly as the author of the first piece of formal criticism in Chinese literature. In the "Lun-wen," 言侖文
"On Literature," Ts'ao P'i attempts a definition of genres and the uses appropriate for each. He discusses the strengths and weaknesses of the outstanding writers of his day. He develops the con-

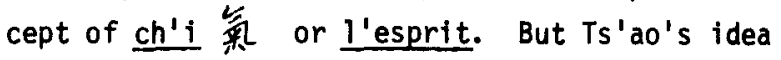
of $\mathrm{ch}^{\prime} \mathrm{i}$ is somewhat broader than 'spirit' or 'inspiration,' it is an inborn concentration of energy or vitality which must reveal itself in certain patterns and modes, and is therefore the keystone of all literary expression. And finally, he comments on the use of literature as a means of gaining personal and enduring fame. While such a motive may not seem particularly praiseworthy, this subjective approach represents a considerable departure from the usual attitude that the function of literature is to teach a moral lesson. Ts'ao $P^{\prime} i$ also write short fu and poems patterned after anonymous yuleh-fu 缐底. His choices of theme and subject reveal the new and more personal approach to literature adopted by writers at this time.

Ts'ao $P^{\prime} i$ is important not only for the contribution that he made to literature, but also for the role he played in Chinese history. As the first ruler of the Wei dynasty (reg. 220-226), he was a major participant in the final downfall of the Han dynasty. He oversaw the partition of the country and inaugurated the period of the Three Kingdoms. Ts'ao P'i's life is a firsthand summation of the events and concerns that were revolutionizing literature and society.

The first chapter of this dissertation summarizes the important historical events that influenced Ts'ao $\mathrm{P}^{\prime} \mathrm{i}$ and shaped the life of China for centuries to come. In the second chapter, the "lun-wen," "On Literature" is translated and analyzed both as to its historical antecedents and its literary significance. The third chapter discusses the development of Chien-an poetics and $i$ ts effect on Ts'ao P' $i$ 's poetry. The fourth chapter contains the annotated translations of the shih, yuleh-fu and fu currently extant that are attributed to Ts ao $P^{\prime} i$. This study attempts to demonstrate the gradual process by which the impersonal was transformed into the personal, and the ballad became the lyric. 322 pages.

TOPOGRAPHY AND COSMOLOGY IN EARLY HAN THOUGHT: CHAPTER FOUR OF THE HUAI-NAN TZU

MAJOR, John S., Ph. D. Harvard University, 1973

The "Treatise on Topography" comprises the fourth chapter of work usually known as the Huainan Tzu or the Huai-nan hung-lieh chieh, written at an academy under the patronage of Liu An, Prince of Huai-nan, and presented to the court of Han Wu-ti not later than 139 B.C. As a comprehensive work on topography, and on the place of the earth and its creatures in the cosmos; as a philosophical document of precisely known date; and as a work that continues the theories of the Tsou Yen school of cosmology in relatively pure form, it is of great importance for the history of the Chinese tradition of cosmology and natural science.

The "Treatise on Topography" of course does not exist in isolation from other early Chinese philosophical works. Rather it draws heavily on a wide range of earlier works, even to the extent of duplicating 
or closely paraphrasing long passages. The most important textual antecedents for this chapter are the "Yu kung" chapter of the Shu ching, the Shanhat ching, Lu-shih ch'un-ch'iu, portions of the Ch $u / z^{\top} u$, and presumabiy the works of Tsou Yen himself, though little of Tsou Yen's own works survives to verify this contention. It also has much in common with other chapters of the Huai-nan Tzu, expecially Chapter Three, the "Treatise on Astronomy." The chapter also draws less heavily on other works of the Warring States period, including Lao Tzu, Chuang Tzu, Kuan Tzu, Mu Ti ien Tzu chuan, and perhaps ChI $\mathrm{Ni}$ tzu. It shares a long passage with the roughty contemporary Ta-Tai $1 i$-chi, and also has affinities of varying strength with other works of Han date, including Tung Chungshu's Ch'un-ch'iu fan-1u, Lieh Tzu, K'ung Tzu Chia-yd, Po hu $t^{\prime} u n g$, and the treatises on geography and on the five elements in the Shih chi. Nevertheless, all this is not to say that this chapter is simply a compilation and restatement of earlier sources, nor that the same information and point of view could be gotten from any of a number of pre-Han and Han works. The value of the chapter lies precisely in the clarity with which Han understanding of cosmology is drawn from disparate sources, coherently re-arranged, and supplemented with original material; the final product is a remarkably clear and cogent presentation of a philosophical tradition that was coming to an end as an independent branch of learning and was about to be subsumed in the syncretism of Han Confucianism.

The "Treatise on Topography" is solidly within the Tsou Yen school of cosmology, wherein all phenomena in the universe (whether "organic" or "inorganic" in Western terms) can be analysed and understood in terms of yin-yang/Five Phase categorical reasoning. Its description of the heavens and the earth follows the kai-t'ien model, wherein the earth is flat or slightly domed and "square" (i.e., defined by the solestial and equinoctial points on the celestial equator), and the heavens are domed and "round" (i.e., defined by the circle of the celestial equator). The treatise further follows Tsou Yen's cosmology in treating the earth as divided into nine great continents. It takes one of these continents as the oikoumene, divided into nine sub-continents, one of which is China. China itself is further schematically divided into nine provinces.

The implied cosmogony of the "Treatise on Topography" is consistent with the famous cosmogonic passage at the beginning of Huai-nan Tzu Chapter One, whereby the Tao divides into yin and yang, which further divide into the Five Phases. From these the "myriad things" are produced. This chapter shows that the "myriad things" are produced by a process of species differentiation of plants, animals, and minerals from first ancestors with Five-Phase correlations. The chapter also mentions the "cosmic triad" of heaven, earth, and man, and uses the numerology of three and nine to account for the gestation periods of various creatures.

The Chinese text of the "Treatise on Topography" is not divided into sections; however, it has proved to be convenient to artificially divide the text into sections for purposes of analys is and commentary, following natural divisions of subject-matter in the text. The nineteen subsections of the chapter thus obtained are as follows:
1. The nine provinces.

2. The dimensions of the oikoumene and the earth's plane.

3. The $K^{\prime}$ un-lun mountains.

4. The rivers of $K^{\prime} u n-7 u n$.

5. The heaveniy mountains; the solar trees.

6. The regions beyond the nine provinces.

7. The "beauties" of the nine directions.

8. Physical and psychological effects of topography on different creatures.

9. The response of all things to their $\mathrm{ch}^{\prime} \mathrm{i}$; the effects of diet on temperament.

10. The numerology of three and nine governs terms of gestation.

11. Taxonomy.

12. The appropriateness of different kinds of water to different crops and kinds of minerals.

13. Characteristics of the inhibitants of the five directions.

14. The Five Phases.

15. The thirty-six countries.

16. Mythical personages and their dwelling-places.

17. The rivers of China.

18. The evolution of plants and animals from first ancestors.

19. The growth and evolution of minerals in the earth.

Taken together, these various subsections provide a remarkabiy clear and "scientific" (that is, not normative or ethical) description of the physical earth, the axis mundi, the magically potent regions where heaven and earth meet, and the mythical personages that live there, the habits and qualities of the earth's myriad living creatures, and of the cosmic principles that govern the behavior of the entire world organism. 